\title{
Challenges for Successful Planning of Open and Distance Learning (ODL) : A Template Analysis
}

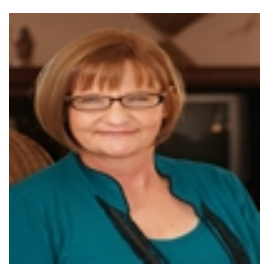

Ansie Minnaar

University of South Africa, South Africa

\section{Abstract}

How to plan an open and distance learning (ODL) unit in higher education is not clearly described in the literature. A number of ODL facilities at residential universities have not been successful because of a lack of planning or because of failure to ensure that all the different systems for ODL delivery were in place and functioning. This paper sheds light on how to plan strategically and how to implement an ODL unit at an existing university.

A template analysis was used to construct a road map for ODL planners. We used this analytical tool to organise data from a large collection of articles, books, and documents from 1980-2010. We purposefully chose template analysis as a document analysis process to foster the recurring themes found in published articles on planning and implementing ODL facilities in higher education.

The results indicate four main strategies for successful implementation of an ODL unit. The template consists of strategic planning, policies, systems, and challenges. It was concluded that the template for ODL planning offers new insight into distance education. It could be used as a foundation for ODL planning, implementation, monitoring, and evaluation. We recommend further research on the template with the aim of theory construction for ODL planning and implementation.

Keywords: Template analysis; challenges in open and distance learning; distance education 


\section{Introduction}

Very often the question arises of what to do when an ODL unit is to be planned and implemented at traditional face-to-face higher education institutions. In many cases these institutions rush to provide technology-enhanced learning or ODL, which is in contrast with their initial goals and strategies, in an effort to stay competitive in the field or for financial reasons. Financial reasons are usually the wrong reasons for implementing ODL or technology-advanced learning. The costs are initially high, and with ever-changing technology, it could end up costing more than face-to-face teaching.

This article is intended to engage academics and academic planners from face-to-face universities in strategic thinking before ODL or technology is implemented with undesirable outcomes. My aim with this article is to shed light on strategic thinking in order to plan ODL and technology-enhanced learning in traditional face-to-face universities in a step-by-step manner. The purpose of the literature review was to construct a road map for ODL planners and implementers in higher education. From the study it is clear that ODL cannot be implemented successfully without strategic planning and a clear mandate for ODL.

The promise of distance education remains unfulfilled in many education institutions. Despite many good intentions, education institutions are still failing to recognise particular key planning and implementing steps which could make the difference in successful and sustainable distance education initiatives. Historically, the growth and success of distance education were fuelled by the need to increase access to learning and the availability of technology for delivery. There are many more challenges affecting the planning of ODL, such as globalisation, joint course development, material sharing, computer and information technology (Watkins \& Kaufman, 2003).

The greatest challenge for education institutions in moving towards ODL is to adopt a singular vision, policies, and procedures for ODL implementation. In general, ODL planning is focused on budget and staffing issues and not on the critical pedagogical issues of ODL. However, ODL is so much more than just a teaching mode or method; it is a distinct and coherent field of education which is focused on new delivery methods with a pedagogical philosophy (Levy, 2003).

To add to this problem, there are no clear guidelines available to follow when planning open and distance learning in higher education (Gunawardena \& McIsaac, 2004). Academic planners of ODL need to think about the reasons for offering courses via ODL and whether it is possible to offer the course via ODL. Before any investments are made in distance education, a rigorous needs assessment of the educational institution may justify another option or other difficult decisions may need to be considered first.

When education professionals ponder on the feasibility of distance education programmes and whether or not to implement ODL, their first impulse is to search through the curricula to determine which courses can easily be translated into online, 
video, or digital formats. Rumble (2003) makes it clear that educators must understand that distance education may not necessarily be the best solution to their problems in education. Meanwhile, each year, the number of higher education institutions offering distance education learning courses continues to grow significantly.

\section{Literature Review}

Distance education and ODL are currently important topics for educational planners, administrators, academics, and policymakers because of the growth of distance learning and technology-enhanced learning (Bishop \& Spake, 2003; Levy, 2003; Pacey \& Keough, 2003). According to Bishop and Spake (2003), policymakers are faced with an array of choices related to planning ODL, such as infrastructure, student support, support to academics for their changing role as distance educators, and costs, to name a few. To add to this, distance education delivery is faced with changes such as the movement from correspondence-type delivery to open access and technology-enhanced learning where technology is changing constantly (Bishop \& Spake, 2003).

Similarly, electronic or technology-enhanced courses do not necessitate more facilities, but institutions will incur capital outlays such as computer hardware and software and their updating and maintenance, additional personnel costs such as webmaster, instructional designers, course administrators, and e-tutors, and computer assistance to students. The most important aspect is the quality of education and the threat of dishonesty in technologically advanced learning environments (Lezberg, 2003).

The history and evolution of ODL is well documented, but the planning process of an ODL unit within a university and how to ensure quality education to students in the ODL mode are vague. The literature available deals with certain aspects of planning and implementation of ODL. What matters most is that consideration must be given to the different challenges when an ODL unit is planned (Watkins \& Kaufman 2003).

From the template analysis it is clear that there is a gap in the literature regarding a practical guide for planning ODL. Furthermore, it should be noted that this article does not claim to provide a comprehensive list of all academic publications or Web sites. The geographical scope of this template analysis provides a worldview on the planning of ODL units, departments, or colleges at traditional face-to-face universities. It is my view that this template could be used as a guide to plan an ODL institution as well.

The systems view as described by Moore and Kearsley (2005) guided the template analysis. This systems theory has different levels of complexity and is influenced by governments, national and international policies, and challenges. For the purpose of this template analysis, the following processes and elements of a distance education system were analysed: strategic planning, administration, staffing and training, control and monitoring for quality, policy, organisation and culture, course development, 
support structures, teaching and learning processes, and challenges (Moore \& Kearsley, 2005). The final template was reconceptualised and simplified into four main codes, namely strategy, policy, systems, and challenges.

\section{Methods}

This paper addresses challenges to plan and implement an ODL unit in an existing higher education institution. The key component of this study was the design and production of a template for planning and implementing ODL using peer-reviewed journal articles and books on distance education. In this study, we drew on more than 30 peer-reviewed and published literature sources to present a template for planning an ODL unit.

A relatively new development in organisational research has been the application of template analysis to structure qualitative data (Waring \& Wainwright, 2008). One of the most common approaches to content analysis is thematic analysis, where the coding scheme is based on categories designed to capture the dominant themes present in the text (Attride-Stirling, 2001; Hardy \& Bryman, 2009). Thematic analysis is ideally suited to get a clear picture of the basic content of text. Therefore, the purpose of the study was to analyse the literature on ODL planning and implementation to develop a template for ODL planners.

The research question stated for this study was as follows: What needs to be considered in higher education institutions embarking on planning an ODL unit?

There are multiple interpretations to be made from the phenomenon of planning ODL. The contextual constructivist position in this study lent itself to reflexive and flexible ways of examining the issues and challenges in ODL planning (Braun \& Clarke, 2006). The study therefore did not narrow in on one best method to plan ODL facilities. We provided a template for ODL planners to use and to choose from, and they can decide how and when they want to implement the different aspects of the template.

The data used in this study were sourced using reliable databases and peer-reviewed journal sources, books, and documents. We started with 55 literature data sources and excluded 25 of these based on our inclusion and exclusion criteria. Data sources were mined using electronic databases available at Unisa. Databases searched in this study were Eric, EBSCO, ProQuest, Sabinet, Theses Canada, FirstSearch, SAGE, Google Scholar, and Theses and Dissertations. 


\section{Planning of Open and Distance Learning/ Education, Strategic Planning in ODL, Challenges in ODL}

Inclusion and exclusion criteria were used to identify the relevant sources. Inclusion criteria were aspects such as publication date and articles published from 1980 until 2010 on ODL or distance education. Peer-reviewed research articles as well as subject specialist articles and books on planning distance education or ODL were included. Exclusion criteria were articles published before 1980, articles which did not refer to higher education, distance education, and ODL, and articles which were not peer reviewed.

The process of template analysis on the 30 data sources involved the identification of themes through careful reading and rereading of the data. This is a form of pattern recognition within the data, where emerging themes become the categories for analysis. The template was based on the preliminary scanning of the data sources (Cassell, 2008; King, 2006; Woodhouse, 2006).

Reliability and credibility of the codes needed to be tested. Another researcher verified and checked the codes with the literature. We applied the template codes and added additional codes throughout the process of data analysis. We connected the codes and identified the themes, and corroborated and legitimated the coded themes by moving between the template, literature, and themes while considering the coded themes. Codes were written with reference to the code label or name, or the definition of what the theme entailed (Fereday \& Muir-Cochrane, 2006).

\section{Inclusion Criteria for the Template}

Different definitions applied for each code. More definitions were added as the data analysis proceeded. For a new level two or three codes were included, and careful data checking and validation were done. For example, code 1 included aspects in the literature which referred to the definition. Strategic issues, which included purpose statements, vision, mission, strengths, weaknesses, opportunities, and threats (SWOT) action plans, goals, and objectives, were aspects listed under code 1. The inclusion criteria for code 2 included policies in education, the alignment of policies with the strategy and policies on teaching and learning, governance, faculty, or academics, legal, technical, and philosophical policies.

For code 3, the systems included aspects of communication, human resources, financial management, and administration. Code 4 initially included aspects regarding the culture of the education institution, namely values, morale, interrelationships, commitment, diversity, and a sense of belonging. However, these aspects were recategorised under policies where they belong. Code 4 then referred to challenges which included basic infrastructure to deliver ODL courses, such as costing, appropriate basic technologies, basic technology services such as wiring, networking, connections, 
computers, software, and licensing, technological support for staff and students, staff development, and strategic alignment with ODL.

\section{Results of the Study}

The final template consists of four codes, namely strategy, policy, systems, and challenges. The first level-one code is strategy, which comprises ten level-two codes: the mandate, refinement of purpose statement, vision, mission, analysis of internal environment, analysis of external environment, and formulation of strategic issues, goals, objectives, action plans, and decisionmaking.

The second level-one code, policies, encompasses another set of key issues for the study. Five level-two codes, 21 level-three codes, 8 level-four codes, and 103 level-five codes emerged from the literature on this theme. Policy issues serve as guidelines to meet goals and in planning an ODL unit these aspects play a key role in the success of the initiative. Twelve level-two codes were identified as the basic framework aspects for policies in ODL with 30 level-three codes specifying particular policies and aspects of policies in ODL. We recategorised "Culture" under policies as it is mostly an aspect of an organisation that develops later with organisation growth and that involves policy issues. See Table 1.

The third level-one code, namely systems, encompasses key issues in the planning of ODL facilities. To start with, this code accounts for 29 level-two codes and 16 level-three codes. The 29 level-two codes are management systems, which include a bureau of management information and a quality improvement system. This code includes ICT services, such as information and communication technology systems, information communication, telecommunication services, and computer service and support systems for students and academics. The financial system consists of financial management, financial autonomy and transparency, how the money is spent, and financial control as a measurement of effective spending. Teaching and learning includes curriculum, examination, undergraduate and postgraduate student affairs, language service, assignments, dispatch system, and administrative support systems. The staffing or human resource system includes work responsibilities, skills to perform job descriptions, and opportunities for training in place to administer the staff for ODL. Support systems comprise the call centre, examination administration, graduation ceremony, bureau of student counselling and career development, student financial aid bureau, bureau of learning development, safety services, and student support and library services.

"Challenges" was the fourth and last level-one code. Five level-two codes and 22 levelthree codes were identified. The 22 level-three codes are purely descriptive: basic infrastructure to deliver ODL courses, which is expensive, appropriate basic technologies, basic technology services, such as wiring, networking, connections, 
computers, software and licensing, and technological support for staff and students. Staff development, strategic alignment with ODL, corporate learners, professional enhancement learners, traditional learners and degree-completion adult learners are more challenges facing ODL planners.

Lastly, we linked the codes and identified the themes, corroborated and legitimated the coded themes by moving between the codebook, literature, and the themes, and considered the coded themes. Codes were written with reference to the code label or name, the definition of what the theme covered, and, lastly, a description of how to know when the theme occurs, as displayed in Table 1.

\section{Discussion of Results}

The most difficult decision that we had to make was the decision to stop the process of template analysis. No template can be considered as final, as new data sources emerge all the time. After seven months of template analysis and working with the data by reading the data sources several times, we considered the template as final. The final template consists of four level-one codes, namely strategy code 1, policies code 2 (which became code 2 because of the magnitude and obvious order importance of this code), the systems code renamed code 3 , and challenges code 4.

From the template analysis, it was clear that a strategy for ODL planning and implementation must be mandated by government. To move from a face-to-face institution to ODL needs redefining of the institution as a whole. Strategic planning for ODL needs a decision from institutional management to embark on the initiative. A SWOT analysis, a gap analysis, and a functional analysis need to be done to establish the feasibility and criteria for planning. Aspects such as hardware, software, distance delivery technologies, technical staff, and academic support for staff are important considerations. Instructional development support staff, administrative support, student services, financial plans, costing of distance education, and staff development and training should be in place before ODL is implemented (Knipe, Van der Walt, Van Niekerk, Burger, \& Nell, 2002; Levy, 2003). Many more processes and structures will be needed for successful implementation of ODL, as we discovered during our template analysis journey.

Code 2, policies in ODL, was the largest code in this study. From this template analysis it is evident that a government mandate and institutional guiding policies are of the utmost importance for the delivery of distance education. The literature is clear on the importance of guiding policies in ODL and most of the data sources refer to policies in ODL. The presence of policies can provide a framework for operation. An agreed-upon set of rules that explain all participants' roles and responsibilities is essential; the lack of this can compromise the quality of programmes (Braimoh \& Lekoko, 2005). 
ODL institutions need policies for governing and operations which include aspects such as geographical, service area, and physical boundaries. Governing policies such as the board, collaborations, course offerings, curricula, support, staff training, conflict management, profit sharing, and control of resources and certification must be developed (Braimoh \&Lekoko, 2005).

An ODL institution will need human resource policies on compensation, evaluation and course evaluation, promotion, performance management, and intellectual freedom. Regarding staff support, staff development/ training, skills training, course/programme support, local facilities, and leave aspects need to be addressed in different policies (Gellman-Danley \& Fetzner, 1998; Simonson \& Bauck, 2003).

Legal policies should be included to guide staff on aspects such as intellectual property, plagiarism, liability, educational technology, and labour relations. ODL institutions need student policies to regulate aspects such as registration, resources, training and tutoring, assessment, and student support services. Technical policies, including ICT issues, internet, and contractual agreements, are crucial for the smooth running of ODL. ODL needs fiscal policies on a number of student issues and state funding and contracts.

With regard to code 3, system, in Table 1, all support functions must be in place, such as curriculum and course development system, call centre, examination administration centre, and undergraduate student affairs. Student support services such as postgraduate student affairs, graduation ceremonies, bureau of student counselling and career development, student financial aid bureau, bureau of learning development, and student support form the backbone of ODL. Library services, a bureau of management information, safety services, telecommunication services (ICT), language services, assignments, dispatch, state-of-the-art printing services, academic directorates, colleges, departments, institutes, and units all provide specialised support to the academics and students and are focused on quality ODL delivery and improvement of teaching and learning.

This template analysis indicated the main challenges for ODL, of which start-up costs and expenses, learner profile, competition for students, and student support were the most important. The new student base that grows up in a technology-rich environment might challenge the usage of technology in higher education and specifically in ODL. This is a challenge to get academics to use technology effectively in ODL. Another challenge for ODL providers and academics could be the fact that students who were rejected at other institutions register at ODL institutions and are in fact the weak students. The combination of very young weak students, professional enhancement students, and traditional students could challenge teaching and learning strategies in ODL. In reality there is competition among universities as students are viewed as consumers. Another challenge for ODL is the diverse needs of ODL students.

Student support is always an important issue for universities. From the literature on ODL it is clear that student support in ODL needs awareness programmes, firstly, as 
students are not aware of the support available. All staff at ODL institutions must receive special training regarding support services to be able to point students in the right direction when the need arises.

Academic support to ODL students is of the utmost importance. In ODL where there is little or no face-to-face contact, academic support and feedback sometimes become the only interaction with the student. Academic support needs to be investigated and effective support needs to be a given in ODL. This means more costs, academic appointments in ODL, more technology for student support, and more training of academics to use the technology to support the students (McKay \&Makhanya, 2008).

Table 1

Template for the Study on Access for Success in ODL Planning

Code 1

Label Strategy

Definition Strategic planning is proactive, dynamic and directed toward a culture of change (Levy, 2003).

Description

1. Mandate from government vs. globalisation (Berge, 2003)

2. It is a redefining of the organisation as a whole, the entire context

3. Systematic strategic planning process model:

- Planning initiation: a decision to start

- Planning guidance and scheduling: leadership intent is articulated, clear purpose of the planning effort

- Analyses: environmental and the needs/ gap analysis and SWOT analysis

- Mission refinement: defined in measureable terms that provide a clear and concise picture of what is to be accomplished and why

- Assumptions: logical, realistic and essential for planning

- Strategy development and courses of action, also course of action (COA) development (Rovai, Ponton 
\&Baker, 2008)

- Functional analysis: COA developed must be reviewed and compared against a number of criteria

- Implementation: resource allocation or tactical plans

- Assessment: post-implementation assessment and formative assessment during the implementation

- Periodic review to identify and assess the impact (Pisel, 2008)

4. Purpose: involvement of all the stakeholders to determine the purpose and goals for ODL programmes (Levy, 2003)

5. New vision is inspirational, defines success; correct timing, organisational buy-in and shared (Levy, 2003; Pisel, 2008). The old vision cannot be moulded into the image of existing residential-based programmes (Levy, 2003)

6. Mission is ever-changing (Berge, 2003); integrated with the institutional mission (Berge \& Schrum, 1998)

7. Financial planning and costs, why distance education? Adequate number of qualified academics available who are willing to teach at a distance; additional costs of programme development (Berge \& Schrum, 1998)

8. Investigate successful models at other organisations (Berge, 2003)

9. Identify solution requirements and alternative solutions (Watkins \& Kaufman, 2003)

10. Formulation and alignment of strategic issues, goals, objectives and action plans

11. Decisions on:

- the type of ODL system (paced or not)

- $\quad$ self-paced or programme systems 
- open access or not (student selection for admission)

- single or dual mode institution

- technological capacity

- attendance requirements

- $\quad$ certification and accreditation (COL, 2004)

Code 2

Label Policies

Definition A policy is defined as a written course of action, such as statute, procedure, rule or regulation that is adopted to facilitate programme development (Simonson \& Bauck, 2003).

Distance education policies should promote, encourage and support the orderly development of distance education as well as associated technologies, infrastructure and staff development. These policies should help to enhance the effectiveness and management of distance education at minimal economic and social costs (Gokool-Ramdoo, 2009).

Description 1. Content of the policy

- Involves the vision, goals, critical success factors, strategies and elements

- The content of policy generally involves the formulation of a problem, proposes solutions, states the goals of the policy and outlines the strategy for implementation

- Academics should be involved in determining the priorities, policies and procedures for implementing ODL from the beginning (Levy, 2003)

2. Context in which the policy operates

Policies do not exist in isolation but are deeply interconnected with factors such as demographic, sociopolitical, economic, public service, specific sector and the department (Simonson \& Bauck, 2003)

3. Processes applied 
- Processes refer to the way in which policies are implemented

- Processes involved include:

o policymaking stages

o organisational processes - planning, performance management, decisionmaking, culture, communication, co-ordination, leadership, conflict management, learning, technology

o change management (Gokool-Ramdoo, 2009)

4. Actors involved

- Actors involve the stakeholders and their values, interests, influence and relationships

- In order to assess how effectively a policy is implemented, we need to understand the relationships, values, interest and behaviour of the different stakeholders

- Conducting a stakeholder analysis could assist in developing insight into the interaction of the various actors (Levy, 2003)

5. Categories of policies in ODL institutions

- ODL policy (Nonyongo, 2009)

o ODL policy for the institution

- ODL policy for governing department (Nonyongo, 2009)

- Philosophical policies

o Vision

o Mission

o Activities (Levy, 2003)

- Academic policies

o Students 
- Admission policies (Gellman-Danley \& Fetzner, 1998)

- Assessment policies (Meyer et al., 2012)

- Academic records

- Academic calendar

- Teaching and learning

- Support

- $\quad$ Credit transfer (Gellman-Danley \& Fetzner, 1998)

o Academic staff

- Evaluation

- Credentials

- Research and ethics (Gellman-Danley \& Fetzner, 1998)

o Curriculum

- Course development

- Accreditation

- Course approval

- Course evaluation (Gellman-Danley \& Fetzner, 1998; Simonson \& Bauck, 2003)

- Quality improvement (Braimoh \&Lekoko, 2005)

- Completion criteria

- Policies for governance and operations

o Geographical

o Consortia agreements

o Service area, local versus international (Gellman-Danley \& Fetzner, 1998) 
o Regulations that define the physical boundaries for recruitment and services (Gellman-Danley \& Fetzner 1998)

o Management and structure/ governance

o Board

o Provider contracts (Gellman-Danley \& Fetzner, 1998)

- Human resources policies

o Compensation

o Compensation for the development and instructional expertise in working with distance learning initiatives (Gellman-Danley \& Fetzner, 1998; Simonson \& Bauck, 2003)

o Overtime compensation

o Evaluation

o Course evaluation

o Promotion

o Performance management

o Intellectual freedom

o Support

o Staff development/ training, skills training

- Course/ programme support

o Local facilities

o Leave (Simonson \& Bauck, 2003)

o General

o New policy formulation or revising existing policies on:

- class size and workload 
- development incentives

- intellectual property

- assignment of full-time or adjunct academics

- "master teachers" shared among institutions

- office hours

- $\quad$ academic training workload (Gellman-Danley \& Fetzner, 1998)

o Job satisfaction

o Culture

o Support for the values of the organisation

o Values and the generation of it

o The central values that govern the organisation

o Level of morale in the organisation

o Motivated to work

o Type of dynamics amongst colleagues

- A willingness to share ideas

o Problems resolution

o A forum or opportunity to raise problems

o Criticism

o The level of commitment

o Give full potential

o Racial/gender/ class/political/sexual preference/age etc. conflicts

o Conflict management

o The organisational policies 
o Feeling part of the organisation

o Important role of everyone

o Acknowledgement for the work that they do

o Beliefs and norms

o Organisational values

o Language

o Innovation

o Xenophobia (Braimoh \& Lekoko, 2005; Parrish \& Linder-VanBerschot, 2010)

- Legal policies

o Intellectual

o Copyright

o Liability

o Student

- Academics

o Organisation

o Educational technology

- HR and labour relations regulations (Gellman-Danley \& Fetzner, 1998)

- Non-academic

o Student counselling

o Library

o Marketing

o Privacy

o Access to learning facilities and equity 
o Material deliveries

o Textbooks

o Equipment and software (Gellman-Danley \& Fetzner, 1998)

- Technical policies

o Physical delivery system/network

o System reliability

o Access and connectivity

o Setup, equipment and maintenance

o Usage of appropriate technology

o Sustained funding for ICT

o Expertise and technical know-how

o Contractual

o Agreements (Braimoh \&Lekoko, 2005)

- Fiscal policies

o Special fees

o State funding

o Administrative costs

o Telecommunication costs

o Tuition rate, technology fee, FTE's consortia contracts, government fiscal regulations (Gellman-Danley \& Fetzner, 1998)

o How much will a course cost? Will there be a technology fee? (Gellman-Danley \& Fetzner, 1998)

o Fees and contractual arrangements for institutions providing venues and resources ("receiving sites") (Gellman-Danley \& Fetzner, 1998; Mays, 2005) 
Code 3

Label Systems

Definition A distance education system consists of all the component processes that operate when teaching and learning happens at a distance, according to Moore and Kearsley (2005).

Description

1. Management system for distance education (Berge, 2003); responsibilities such as pedagogical and organisational issues (Berge, 2003)

2. Information communication

- Does everyone have access to the flow of information?

- Are your suggestions heard?

3. Work responsibilities

4. Skills to perform their job descriptions

5. Opportunities for training

6. Career plan

7. Performance management

- Incentive for performance

- Performance appraisal

- Promotion

- Recruitment and selection

- Affirmative action policy

- Nepotism

- Induction process (Berge, 2003)

8. Financial management

- Financial autonomy 
- Transparency

- How is the money spent and raised?

- Financial control systems (Berge, 2003)

9. Administrative systems

- How is work administered?

- How long does it take for administrative work to be completed?

- $\quad$ Time management (Berge, 2003)

10. Curriculum and course development system

11. A call centre

12. Examination administration

13. Undergraduate student affairs

14. Postgraduate student affairs

15. Graduation ceremonies

16. Bureau of student counselling and career development

17. Student financial aid bureau

18. Bureau of management information

19. Bureau of learning development

20. Safety services

21. Student support

22. Library services

23. Telecommunication services (ICT)

24. Language services

25. Assignments

26. Dispatch 
27. State-of-the-art printing services

28. Academic directorates, colleges, departments, institutes and units which all provide specialised support to the academics and students

29. Quality improvement (Inglis, 2005; Milheim, 2001; Normand, Littlejohn \& Falconer, 2008)

Code 4

Label Challenges

Definition Proactively identifying and responding to strengths, weaknesses, opportunities, threats as well as emerging opportunities and barriers such as academic compensation and time, organisational change and lack of technical expertise and support in distance education (McKay \& Makhanya, 2008).

Description For ODL there are six strategic challenges.

1. Start-up costs for a distance education programme are expensive

- Basic infrastructure to deliver ODL courses is expensive

- Appropriate basic technologies

- Basic technology services such as wiring, networking, connections, computers, software and licensing, technological support for staff and students

- Staff development

- Strategic alignment with ODL (McKay \& Makhanya, 2008)

2. The new student base that grew up using information technology

- Corporate learners

- Professional enhancement learners

- Traditional learners 
- Degree-completion adult learners

- Recreational learners

- Students who were not successful at residential universities (McKay \& Makhanya, 2008)

3. The competition among universities has intensified as a result of distance education

- Students are viewed as consumers and can study anywhere, any time, any place and at their own pace

- The emergence of corporate universities (in-house training facilities to cater for the changing labour market)

- The rising costs of tuition at traditional universities

- Dealing with both society's and students' needs (McKay \& Makhanya, 2008)

4. Marketing anticipated and the process which enables the student needs to be identified

- Client/ potential students' needs must be identified and satisfied

- Recruitment plans (McKay \& Makhanya, 2008)

5. Student support

- Access to a range of student support services such as registration and admission, financial aids services and technology

- Three areas for support:

o Enrolment

o Instruction

o Support (Howell, Williams \& Lindsey, 2003) 


\section{Recommendations}

I recommended that higher education institutions (traditional face-to-face institutions) that want to implement ODL into their offerings start small with small successes to draw people to the change process. In the end it is easy to get the buy-in of academics when small successes are a reality in ODL delivery. The image of ODL can easily be damaged when too many courses are developed and offered too quickly. Developing ODL courses could be a very time-consuming process and the pressure of mass education could hamper quality course construction. When the strategy, policies, and systems are aligned for ODL delivery, the most important aspect of the systems usually seem to be forgotten. Most academics came from face-to-face institutions and course development in an ODL mode with ODL philosophies may be unfamiliar to them. Academic and other staff need time to develop ODL skills. It can take up to five years to build up a core staff establishment that is equipped to fully operate ODL (COL, 2004).

Next, when an ODL unit is planned, it is recommended that the template be used and adapted to specific needs. Furthermore, it is recommended that ODL be kept small and confined to certain courses and target groups. Planning of ODL should follow the sequence of the template. Start with strategic and visionary thinking, taking into consideration the SWOT analysis and challenges posed by higher education, social, and economic forces. During the strategic planning phase, planners of ODL need to buy in to a singular vision to move forward. It is recommended that the ODL policy and the mandate from government on ODL be clear to ensure alignment of all policies and processes for ODL delivery.

\section{Conclusion}

From the results of the study it is clear that the implementation of ODL needs careful and systematic planning to ensure success. A great deal of thought should go into planning and analysis of markets for ODL. As with any other system, ODL becomes cost-effective when it can take advantage of economies of scale. This means that the more users of the system, the lower the cost for each person or, in the case of education, the student.

The division of labour is familiar in other walks of life, but in education, specialisation seems not to be the practice. In traditional face-to-face classrooms, individual teachers develop and deliver their own courses (Care \& Scanlan, 2001). Educators try to be everything to everyone and to be experts in communication, curriculum design, course design, assessors, motivators, facilitators, as well as content experts. This could be wasteful in ODL and simply adding new and more technology will not result in good teaching and learning. For ODL to be successful, it is important to move to a system where teachers are the specialists within a system (Casey, 2008; Moore \& Kearsley, 2005). 
The template analysis on ODL planning clearly illustrates that systems for ODL delivery must be well developed before ODL can be implemented. We developed four sets of insights from our analysis, each integrating structural and process elements in planning and implementing ODL facilities.

First we saw the dynamics between the processes of strategy, policies, and systems. We became aware of the impact of the challenges on planning processes in ODL. Each of the processes incorporates a set of decisions and is shaped by certain characteristics. There is infinite potential for overlap and interplay between strategy, policies, and systems which are influenced by challenges. This study indicated that strategy precedes policy and systems. Different challenges impact continuously on all plans and processes (Olugbenga, 2010).

Secondly, different policies for ODL need to be drawn up, the most important being the ODL policy for the organisation. All other policies must be aligned with this ODL policy. Following the policy process is the systems which need to be put in place for the smooth running of ODL. Effective ODL delivery needs certain support systems to function.

Thirdly, the systems must be put in place and operational before ODL is implemented to ensure service delivery. In this study, we found that systems needed for ODL to be successful are complex and huge. No organisation could survive without a collection of operational systems in place. ODL relies on a wide variety of systems to function smoothly to ensure student satisfaction.

The challenges in ODL include economic and social changes, technology advancements, computers and software, and student demographic changes. More research and specific reflective research needs to be done on ODL planning and implementation. The template for ODL unit planning provides a clear guideline for ODL planners and the next logical step would be to test the template further and develop it into a model for ODL planning and implementation.

There are three reasons why ODL must not be implemented too quickly and why it must not be treated as a short-term solution to long-term problems in education. Higher education providers, especially face-to-face learning institutions, have been tempted to set up new ODL facilities with large student numbers. Then, very soon they realise that good planning and student support systems need to be in place to ensure quality ODL (Moore \& Kearsley, 2005).

This template analysis indicates a careful and systematic planning process for ODL. Political, economic, and social challenges need to be taken into consideration in strategic analysis and planning for ODL. If this risk analysis is not done, the risk of failure might be high (Moore \& Kearsley, 2005). We further concluded that for ODL to be implemented successfully, staff must be reskilled and developed since ODL is a change process which has a domino effect on all aspects of learning and teaching. The role of unions could pose a challenge for ODL planners and implementers of policies 
and therefore need consideration at all stages of planning and implementation, especially regarding human resource issues.

The best way to plan ODL facilities is to do so in a sequential roll-out fashion. ODL planning starts with strategic planning, followed by the development of ODL policies for alignment with all efforts, strategies, and processes. The greatest effort will be to put the systems in place for ODL delivery and support. ODL organisations and planners must continuously be mindful of challenges facing ODL delivery. It might be a good strategy to start ODL with teacher education since teachers are invariably keen, disciplined ODL students (COL, 2004; Moore \& Kearsley, 2005).

Finally, it is of the utmost importance for the success of ODL implementation that the systems for ODL delivery be in place and working (training may be needed) before ODL students are admitted into the system. A well-developed student support system is a guarantee for success in ODL teaching and learning (Segobye, 2007). Lastly, this template could be used to guide government decisions on how to plan and implement ODL institutions. It could be a useful tool for academic planners to plan and implement ODL and technology-enhanced learning. ODL institutions could use the template as a training tool for staff (academic, administrative, and support staff) to ensure that everyone understands ODL and their specific place and task to enable student success. 


\section{References}

Attride-Stirling, J . (2001). Thematic networks: An analysis tool for qualitative research. Qualitative Research, 1(3), 385-405.

Berge, Z. L. (2003). Planning and managing distance training and education in the corporate sector. In M. G. Moore \&W. G. Anderson (Eds.), Handbook of distance education (pp. 601-610). NewJ ersey: Lawrence Erlbaum Associates.

Berge, Z. L., \& Schrum, L. (1998). Linking strategic planning with programme implementation for distance education. CAUSE/ EFFECT J ournal, 21(3), 1-17.

Bishop, J . S., \& Spake, D. F. (2003). Distance education: A bibliographic review for educational planners and policymakers 1992-2002. J ournal of Planning Literature, 17(3), 372-391.

Braimoh, D., \& Lekoko, R. (2005). The need for policy framework in maintaining quality in open and distance education programmes in Southern Africa. Turkish Online J ournal of Distance Education- TOJ DE, 6(4), 1-8.

Braun, V., \& Clarke, V. (2006). Using thematic analysis in psychology. Qualitative Research in Psychology, 3, 77-101.

Care, W. D., \& Scanlan, J . M. (2001). Planning and managing the development of courses for distance delivery: Results from a qualitative study. Online J ournal of Distance Learning Administration, IV(II), 1-7.

Casey, D. (2008). A journey to legitimacy: The historical development of distance education through technology. Techtrends, 52(2), 45-51.

Cassell, C. (2008). Template analysis. In R. Thrope \& R. Holt (Eds.), The SAGE dictionary of qualitative management research (pp. 1-2). Thousand Oaks: Sage.

Cassell, C., \& Symon, G. (2006). Essential guide to qualitative methods in organisational research. Thousand Oaks: Sage.

Commonwealth of Learning (COL). (2004). Planning and implementing open and distance learning systems: A handbook for decision makers. Vancouver.

Fereday, J ., \& Muir-Cochrane, E. (2006). Demonstrating rigor using thematic analysis: A hybrid approach of inductive and deductive coding and theme development. International J ournal of Qualitative Methods, 5(1), 80-92. 
Gellman-Danley, B., \& Fetzner, M. . . (1998). Asking the really tough questions: Policy issues for distance learning. Online J ournal of Distance Learning Administration, I(1), 1-8.

Gokool-Ramdoo, S. (2009). Policy deficit in distance education: A transactional distance. The International Review of Research in Open and Distance Learning, 10(4), 1-21.

Gunawardena, C. N., \& McIsaac, M. S. (2004). Handbook of research for education. London: Sage.

Hardy, M., \& Bryman, A. 2009. Handbook of data analysis. London: Sage.

Howell, S. L., Williams, P. B., \& Lindsay, N. K. (2003). Thirty-two trends affecting distance education: An informal foundation for strategic planning. Online J ournal of Distance Learning Administration, VI(III), 1-18.

Inglis, A. (2005). Quality improvement, quality assurance and benchmarking: Comparing two frameworks for managing quality processes in open and distance learning. The International Review of Research in Open and Distance Learning, 6(1), 1-13.

King, N. (2006). Using templates in the thematic analysis of text. In C. Cassell \&G. Symon (Eds.), Essential guide to qualitative methods in organisational research (pp. 256-270). London: Sage.

Knipe, A., Van der Walt, G., Van Niekerk, D., Burger, D., \&Nell, K. (2002). Project management for success. Sandown: Heinemann.

Levy, S. (2003). Six factors to consider when planning online distance learning programmes in higher education. Online J ournal of Distance Learning Administration, VI(1), 1-19.

Lezberg, A. K. (2003). Accreditation: Quality control in higher education. In M. G. Moore \&W. Anderson (Eds.), Handbook of distance education (pp. 425-435). New J ersey: Lawrence Erlbaum Associates.

Mays, T. (2005). Costing distance education and open learning in sub-Sahara Africa. Open Learning: The J ournal of Open and Distance Learning, 20(3), 211-225.

McKay, V., \& Makhanya, M. (2008). Making it work for the South: Using open and distance learning in the context of development. In T. Evans, M. Haughey \& D. Murphy (Eds.), International handbook of distance education (pp. 29-48). Bingley: Emerald. 
Meyer, L. H., Davidson, S., McKenzie, L., Rees, M., Anderson, H., Fletcher, R., \& J ohnston, P. J . (2010). An investigation of tertiary assessment policy and practice: Alignment and contradictions. Higher Education Quarterly, 64(3), 331-350.

Milheim, W. (2001). Faculty and administrative strategies for the effective implementation of distance education. British J ournal of Education Technology, 32(5), 535-542.

Moore, M. G., \& Kearsley, G. (2005). Distance education A systems view. Belmont: Wadsworth.

Nonyongo, E. (2009). Collaboration in open and distance learning: The realities of policy implementation in the Africa region. Africa Education Review, 6(1), 106122.

Normand, C., Littlejohn, A., \& Falconer, I. (2008). A model for effective implementation of flexible programme delivery. Innovations in Education and Teaching International, 45(1), 25-36.

Olugbenga, A. T. (2010). Prospects and challenges of Open University in Nigeria. European J ournal of Social Sciences, 12(3), 362-370.

Pacey, L., \& Keough, E. (2003). Public policy in structional structures and strategic implementation. In M. G. Moore \&W. Anderson (Eds.), Handbook of distance education (pp. 401-416). NewJ ersey: Lawrence Erlbaum Associates.

Parrish, P., \& Linder-VanBerschot, J . A. (2010). Cultural dimensions of learning: Addressing the challenges of multicultural instruction. The International Review of Research in Open and Distance Learning, 11(2), 1-19.

Pisel, K. P. (2008). A strategic planning process model for distance education. Online J ournal of Distance Learning Administration, XI(11), 1-9.

Rovai, A. P., Ponton, M. K., \& Baker, J . D. (2008). Distance learning in higher education. A programmatic approach to planning, design, instruction, evaluation and accreditation. London: Teachers College Press.

Rumble, G. (2003). Modelling the costs and economy of distance education. In M. G. Moore \&W. Anderson (Eds.), Handbook of distance education (pp. 703-716). New J ersey: Lawrence Erlbaum Associates.

Segobye, A. K. (2007). Reflections on the university in Africa: The role of the past in education. Social Dynamics, 33(1), 224-231. 
Simonson, M., \& Bauck, T. (2003). Distance education policy issues: State-wide perspectives. In M. G. Moore \&W. Anderson (Eds.), Handbook of distance education (pp. 417-424). New J ersey: Lawrence Erlbaum Associates.

Waring, T., \&Wainwright, D. (2008). Issues and challenges in the use of template analysis: Two comparative case studies from the field. The Electronic J ournal of Business Research Methods, 6(1), 85-94.

Watkins, R., \& Kaufman, R. (2003). Strategic planning in distance education. In M. G. Moore \&W. Anderson (Eds.), Handbook of distance education (pp. 507-792). New J ersey: Lawrence Erlbaum Associates.

Woodhouse, L. D. (2006). Thematic analysis of documents from the SOPE health disparity elimination research agenda summit: Illuminating competencies for future researchers and practitioners. Health Promotion Practice, 7, 346-353.

\section{Athabasca University $\mathbf{I}$}

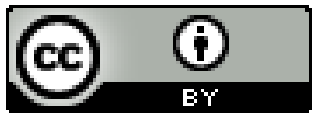

